УДК 631.52:633.491(571.51)

РЕЗУЛЬТАТЫ ИЗУЧЕНИЯ СОРТОВ КАРТОФЕЛЯ

ИЗ РАЗЛИЧНЫХ ЭКОЛОГО-ГЕОГРАФИЧЕСКИХ ЗОН

В УСЛОВИЯХ КРАСНОЯРСКОЙ ЛЕСОСТЕПИ

\author{
Халипский А.Н., Чураков А.А., Абдураимов П.О. \\ ФГБОУ ВО «Красноярский государственный аграрный университет», \\ Красноярск, e-mail: khalipskiya@mail.ru
}

\begin{abstract}
В статье рассмотрены вопросы, связанные с хозяйственной оценкой сортов картофеля в зависимости от региона происхождения. Работа выполнена в 2016-2017 гг. в Красноярском крае. Почва опытного участка - агрочернозём выщелоченный среднемощный среднегумусный тяжелосуглинистый. Изучены 18 сортов, объединённых в эколого-географические группы по происхождению: Красноярский край, Кемеровская область, Западная Сибирь, Европейская часть России, Германия, Нидерланды. По количеству клубней в кусте выделились сорта Памяти Рафика (13 шт., Красноярский край), Гала, Аризона (14 шт., Германия), Невский (15 шт., Европейская часть России) при показателях стандартов: среднераннего Лина - 12 шт., среднеспелого Тулеевский -8 шт. Продуктивность более 1300 г на куст имели сорта Красноярского края (Красноярский ранний, Памяти Рафика), Кемеровской области (Танай), Нидерландов (Аризона), Ленинградской области (Накра). Наибольшую среднюю массу клубня имели сорта Арамис, Тулеевский, Арроу. Крупноклубнёвые сорта имели менее 10 клубней в клоне. Максимальную среднюю урожайность имели сорта из Красноярского края (48,4 т/га), на втором месте из Кемеровской области (40,7 т/га), на третьем из Нидерландов (39,8 т/га). По содержанию крахмала выявлено значительное варьирование в пределах изученных сортов. Минимальное значение показателя зафиксировано у сортов Арроу $(10,2 \%)$ и Коломба (10,6\%). Эти сорта могут быть рекомендованы для диабетического питания. Высоким содержанием крахмала характеризовались сорта Накра $(20,1 \%)$ и Хозяюшка $(20,9 \%)$. Установлено, что максимальная рентабельность получена у сортов, созданных в Красноярском крае (193\%).
\end{abstract}

Ключевые слова: урожайность, качество, содержание крахмала, рентабельность, группа спелости, селекция

\title{
THE STUDY RESULTS OF POTATO GROWING ORIGINATED FROM DIFFERENT ECOLOGICAL AND GEOGRAPHICAL ZONES UNDER CONDITIONS OF KRASNOYARSK FOREST-STEPPE
}

\author{
Khalipskiy A.N., Churakov A.A., Abduraimov P.O. \\ Krasnoyarsk State Agrarian University, Krasnoyarsk, e-mail: khalipskiya@mail.ru
}

\begin{abstract}
The article reveals some issues related to the economic assessment of potato varieties, depending on the region of its origin. The research was carried out during 2016-2017 in the Krasnoyarsk region. The soil of the experimental plot is agricultural chernozem leached medium-power medium-humus heavy loamy. Eighteen varieties were studied, grouped by their ecological-geographical places of origin: Krasnoyarsk region, Kemerovo region, Western Siberia, the European part of Russia, Germany, the Netherlands. In terms of the number of tubers in the bush, varieties of Pamyati Rafiq (13 pcs., Krasnoyarsk region), Gala, Arizona (14 pcs., Germany), Nevsky (15 pcs., the European part of Russia) were selected, compared to the standard breeds: the mid-maturity Lina (12 pcs.), mid-season Tuleyevsky ( 8 pcs.). varieties of the Krasnoyarsk Territory (Krasnoyarsk Early, Pamyati Rafiq), Kemerovo Region (Tanai), Netherlands (Arizona), Leningrad region (Nakra) shown the productivity of more than $1300 \mathrm{~g}$ per bush. The Aramis, Tuleyevsky and Arrow varieties had the highest average tuber weight. Large cultivars had less than 10 tubers in the clone. The varieties from the Krasnoyarsk region are on the first place by the crop-production power ( $48.4 \mathrm{t} / \mathrm{ha})$, the second place took the varieties from the Kemerovo region $(40.7 \mathrm{t} / \mathrm{ha})$, and the third place took varieties from the Netherlands ( $39.8 \mathrm{t} / \mathrm{ha})$. The starch content revealed a significant variation within the studied varieties. The minimum value of the indicator was recorded in the breeds Arrow (10.2\%) and Colomba (10.6\%). These varieties can be recommended for diabetic nutrition. High starch content was found in the varieties Nakra (20.1\%) and Hozyaushka (20.9\%). It was established that the maximum profitability was obtained from varieties created in the Krasnoyarsk region (193\%).
\end{abstract}

Keywords: yield, quality, starch content, profitability, ripeness group, breeding

Многообразие применения картофеля требует использования большого разнообразия сортов с различными качествами, которые реализуются в его сортах и технологиях возделывания. Картофелю, по мнению Е.А. Симакова, достойно принадлежит третье место среди культур мирового потребления, после пшеницы и риса, и четвертое место по объему производства [1].

В связи с этим важная роль в создании сортов отводится созданию исходного мате- риала, его изучению и оценке в различных питомниках. Для этой работы создаются коллекционные питомники, которые формируются на основе мировых коллекций [2].

В настоящее время коллекция сортов картофеля Красноярского государственного аграрного университета насчитывает около 180 образцов. Она включает современные и стародавние селекционные сорта различного географического происхождения, а также местные формы [3]. 
Расширение ассортимента и повышение качества картофеля тесно связано с созданием и внедрением в производственный процесс новых высокопродуктивных сортов. Особое значение для успешного решения столь многогранной проблемы имеет разработка вопросов изучения коллекций исходного материала картофеля с целью вовлечения их в селекционный процесс путем выявления лучших для создания родительских пар.

Цель исследований: оценить сорта картофеля различного происхождения по продуктивности и качеству.

Задачи исследований:

- провести сравнительную оценку сортов картофеля по продуктивности;

- дать оценку сортов картофеля по качеству;

- дать экономическую оценку сортам картофеля по группам происхождения.

\section{Материалы и методы исследования}

Изучено 18 сортов картофеля различных групп спелости и регионов происхождения (табл. 1), 16 из которых внесены в Государственный реестр селекционных достижений и допущены для возделывания в различных регионах Российской Федерации. Не имеют допуска сорта Гурман и Памяти Рафика.

Географические группы составлены таким образом, что включают ранние и сред- неспелые сорта, а также устойчивые и восприимчивые к нематоде.

Из 18 представленных сортов: 2 очень ранних, 3 раннеспелых, 4 среднеспелых и 8 среднеранних.

Почва опытных участков представлена агрочерноземом выщелоченным среднемощным среднегумусным, тяжелосуглинистым. Предшественник - чистый ранний пар. Подготовка пара состояла из весенней культивации стерни зерновой культуры Вспашку пара с оборотом пласта выполняли в конце второй начале 3 декады июля, по мере появления сорняков проводили культивацию пара. На следующий год весной - ранневесеннее боронование. Перед посадкой картофеля проводили глубокое рыхление плоскорезом КПГ 2-1 на глубину $25-27 \mathrm{~cm}$.

Посадку картофеля осуществляли вручную по схеме $30 \times 90$ см после того, как почва на глубине заделки посадочного материала достигнет $+10^{\circ} \mathrm{C}$. В 2016 г. - 26 мая, в 2017 г. - 2 июня. Опыты закладывали в однократной повторности с посадкой двух стандартов: для раннеспелых сортов Красноярский ранний, для среднеспелых Накра. За вегетационный период проводили прополку и окучивание вручную. Уборку картофеля проводили после отмирания ботвы (естественного или вынужденного).

Характеристика изучаемых сортов картофеля

Таблица 1

\begin{tabular}{|l|c|c|c|}
\hline \multicolumn{1}{|c|}{ Наименование сорта } & Происхождение & Устойчивость к нематоде & Группа спелости \\
\hline Красноярский ранний & Красноярский край & rv & раннеспелый \\
\hline Арамис & Красноярский край & rn & среднеспелый \\
\hline Памяти Рафика & Красноярский край & $\mathrm{rn}$ & среднеспелый \\
\hline Тулеевский & Кемеровская область & $\mathrm{rv}$ & среднеспелый \\
\hline Танай & Кемеровская область & $\mathrm{rn}$ & среднеранний \\
\hline Кемеровчанин & Кемеровская область & $\mathrm{rn}$ & среднеранний \\
\hline Накра & Томская область & $\mathrm{rv}$ & среднеспелый \\
\hline Хозяюшка & Омская область & $\mathrm{rn}$ & среднеспелый \\
\hline Лина & Новосибирская область & $\mathrm{rv}$ & среднеранний \\
\hline Адретта & Германия & $\mathrm{rv}$ & среднеранний \\
\hline Гала & Германия & $\mathrm{rn}$ & среднеранний \\
\hline Вега & Германия & $\mathrm{rn}$ & раннеспелый \\
\hline Аризона & Нидерланды & $\mathrm{rn}$ & среднеранний \\
\hline Коломба & Нидерланды & $\mathrm{rn}$ & очень ранний \\
\hline Ароу & Нидерланды & $\mathrm{rn}$ & раннеспелый \\
\hline Метеор & Европейская Россия & $\mathrm{rn}$ & очень ранний \\
\hline Невский & Европейская Россия & $\mathrm{rv}$ & среднеранний \\
\hline Гурман & Украина & $\mathrm{rv}$ & среднеранний \\
\hline
\end{tabular}

П р и м еч а н и е . rn - сорта, устойчивые к нематоде, rv - сорта, не устойчивые к нематоде. 
При уборке вели подсчёт числа кустов на делянке. Определяли число стеблей и их массу, число нетоварных и товарных клубней, их массу с каждого куста.

Для определения содержания крахмала отбирали средний образец весом не более 1000 г каждого сорта. Анализы выполнялись в Красноярской зональной химико-технологической лаборатории. Статистическую обработку урожайных данных и элементов структуры урожая вели по общепринятой методике [4], используя метод дисперсионного анализа. Экономическую эффективность рассчитывали согласно технологическим карам и фактическим ценам, складывающимся в годы исследований.

\section{Результаты исследования и их обсуждение}

Важным селекционным и хозяйственнобиологическим признаком сорта картофеля является количество товарных семенных клубней в клоне.

Для всех образцов коллекции характерна сильная внутрилинейная изменчивость продуктивности, количества клубней, вызванная неблагоприятными погодными условиями. В основном все изученные образцы отличались высоким количеством клубней в кусте (более 10 шт.), за исключением сортов Тулеевский, Арамис и Арроу. Эти со- рта, имея более низкое число клубней, отличались их высокой массой (табл. 2).

Установлено, что большее число клубней в клоне формировали сорта из Германии.

Другим важнейшим показателем, формирующим урожай картофеля, является масса клубней одного клона. Оценка картофеля по массе клубней с одного клона (табл. 3) показала, что этот показатель изменяется как в зависимости от сорта, так и по годам.

В 2016 г. по массе клона ни один из сортов картофеля не превзошел стандартный сорт картофеля Красноярский ранний, районированный с 1994 г. в 5, 10, 11 агроклиматических зонах России.

В 2017 г. сорта Танай (Кемеровская область), Аризона (Голландия) и Невский (Ленинградская область) имели достоверную прибавку к стандарту.

Объединив сорта в группы по экологогеографическому происхождению (табл. 4) были получены данные по урожайности в группах. Средняя урожайность за 2 года самой высокой была у сортов по происхождению из Красноярского края.

На втором месте по урожайности были сорта из группы европейской части России, особенно сорт Невский. Этот сорт в условиях Красноярского края характеризуется стабильно высокой урожайностью на протяжении ряда лет [5].

Оценка сортов картофеля по числу товарных клубней в клоне

\begin{tabular}{|l|c|c|c|}
\hline \multicolumn{1}{|c|}{ Сорт } & 2016 г. & 2017 г. & Среднее \\
\hline Красноярский ранний, стандарт & 12 & 10 & 11 \\
\hline Арамис & 9 & 8 & 13 \\
\hline Памяти Рафика & 14 & 12 & 8 \\
\hline Тулеевский & 9 & 7 & 12 \\
\hline Танай & 12 & 12 & 11 \\
\hline Кемеровчанин & 11 & 9 & 9 \\
\hline Накра & 12 & 10 & 12 \\
\hline Хозяюшка & 10 & 8 & 12 \\
\hline Лина & 13 & 11 & 14 \\
\hline Адретта & 13 & 11 & 11 \\
\hline Гала & $15^{*}$ & 13 & 14 \\
\hline Вега & 12 & 10 & 11 \\
\hline Аризона & $15^{*}$ & 13 & 7 \\
\hline Коломба & 12 & 10 & 9 \\
\hline Арроу & 8 & 6 & 15 \\
\hline Метеор & 10 & 8 & 11 \\
\hline Невский & $16^{*}$ & $14^{*}$ & \\
\hline Гурман & 12 & 10 & \\
\hline НСР & 2 & 3 & \\
\hline
\end{tabular}

Пр и м еч а н и е . * прибавка достоверная. 
Оценка сортов картофеля по общей массе клубней с одного клона, г

\begin{tabular}{|l|c|c|c|}
\hline \multicolumn{1}{|c|}{ Сорт } & 2016 г. & 2017 г. & Среднее \\
\hline Красноярский ранний & 930 & 1810 & 1370 \\
\hline Арамис & 441 & 1500 & 871 \\
\hline Памяти Рафика & 905 & 1759 & 624 \\
\hline Тулеевский & 448 & 800 & 1453 \\
\hline Танай & 896 & $2011^{*}$ & 881 \\
\hline Кемеровчанин & 513 & 1250 & 1006 \\
\hline Накра & 681 & 1332 & 866 \\
\hline Хозяюшка & 699 & 1051 & 789 \\
\hline Лина & 237 & 1340 & 965 \\
\hline Адретта & 577 & 1354 & 745 \\
\hline Гала & 453 & 1036 & 906 \\
\hline Вега & 776 & 1459 & 889 \\
\hline Аризона & 996 & $2186^{*}$ & 479 \\
\hline Коломба & 677 & 1160 & 1001 \\
\hline Арроу & 457 & 502 & 1334 \\
\hline Метеор & 502 & 1500 & 926 \\
\hline Невский & 742 & $1926^{*}$ & \\
\hline Гурман & 363 & 1489 & 58 \\
\hline НСР & 36 & & \\
\hline
\end{tabular}

Таблица 4

Оценка сортов картофеля по урожайности по группам происхождения сорта, т/га

\begin{tabular}{|l|c|c|c|}
\hline Эколого-географическая зона происхождения сорта & 2016 г. & 2017 г. & Среднее \\
\hline Красноярский край & 30,3 & 66,4 & 48,4 \\
\hline Кемеровская область & 26,9 & 56,0 & 40,7 \\
\hline Западная Сибирь & 21,6 & 53,9 & 37,7 \\
\hline Европейская часть России & 20,8 & 65,4 & 43,1 \\
\hline Германия & 24,1 & 48,8 & 36,4 \\
\hline Нидерланды & 28,4 & 51,3 & 39,8 \\
\hline НСР $_{05}$ к стандарту Красноярский ранний & 0,23 & 0,56 & \\
\hline
\end{tabular}

Оценка сортов картофеля по содержанию крахмала, \%

Таблица 5

\begin{tabular}{|l|c|c|c|}
\hline \multicolumn{1}{|c|}{ Сорт } & 2016 г. & 2017 г. & Среднеe \\
\hline Красноярский ранний & 15,1 & 11,2 & 13,2 \\
\hline Арамис & 16,9 & 16,4 & $16,6^{*}$ \\
\hline Памяти Рафика & 20,2 & 15,1 & $17,6^{*}$ \\
\hline Тулеевский & 10,8 & 12,8 & 1,8 \\
\hline Танай & 15,7 & 13,9 & 15,3 \\
\hline Кемеровчанин & 16,2 & 14,5 & $20,1 *$ \\
\hline Накра & 20,7 & 19,4 & $20,9 *$ \\
\hline Хозяюшка & 21,6 & 20,3 & 15,7 \\
\hline Лина & 15,2 & 16,2 & $17,6 *$ \\
\hline Адретта & 17,8 & 17,4 & 13,0 \\
\hline Гала & 12,7 & 13,4 & 12,8 \\
\hline Вега & 14,2 & 11,4 & 10,2 \\
\hline Аризона & 13,0 & 17,4 & 10,2 \\
\hline Коломба & 11,6 & 9,7 & $16,8^{*}$ \\
\hline Арроу & 10,2 & 10,2 & 13,2 \\
\hline Метеор & 20,6 & 13,1 & 12,0 \\
\hline Невский & 13,2 & 13,2 & \\
\hline Гурман & 10,3 & 13,6 & 4,2 \\
\hline НСР & 3,2 & & \\
\hline
\end{tabular}

П р и м е ч а и и . * сорта с высоким содержанием крахмала. 
Оценка сортов картофеля по экономической эффективности

Таблица 6 в зависимости от группы происхождения, среднее за 2016-2017 гг.

\begin{tabular}{|l|c|c|c|}
\hline Группа происхождения сортов & $\begin{array}{c}\text { Урожайность, } \\
\text { ц/га }\end{array}$ & $\begin{array}{c}\text { Себестоимость, } \\
\text { руб./ц }\end{array}$ & Уровень рентабельности, \% \\
\hline Красноярский край & 484 & 4102 & 193 \\
\hline Кемеровская область & 407 & 4451 & 169 \\
\hline Западная Сибирь & 377 & 4651 & 158 \\
\hline Европейская часть России & 431 & 4329 & 177 \\
\hline Германия & 364 & 5301 & 138 \\
\hline Нидерланды (Голландия) & 398 & 5041 & \\
\hline
\end{tabular}

В селекции на улучшение качества картофеля важная роль принадлежит тем сортам, которые в комплексе обладают ими [6]. При оценке сортов по показателям качества мы учитывали в первую очередь содержание крахмала.

В статье Коршунов с соавторами [7], ссылаясь на работу С.М. Прокошева, 1947 г., пишут, что среди пищевых веществ клубней картофеля крахмал занимает ведущую роль. Он составляет 70-80\% сухой массы клубня, или 95-99\% всего количества накапливаемых картофелем углеводов

Оценка сортов картофеля по содержанию крахмала показывает, что его содержание в процентах меняется как в зависимости от сорта, так и по годам (табл. 5).

Содержание крахмала - важный, но не единственный показатель, определяющий вкусовые качества столовых сортов. В наших исследованиях отличные вкусовые качества были у сортов Красноярский ранний, Гала, Коломба, Арроу, Тулеевский, Вега, Танай, характеризующихся средним содержанием крахмала (табл. 5).

Сорт, по мнению Л.А. Калининой, А.В. Новикова [8] - наиболее эффективное и доступное средство повышения урожайности и качества продукции в изменяющихся экономических условиях.

Оценка сортов картофеля по урожайности, себестоимости и уровню рентабельности (табл. 6) показала, что лучшими по этим показателям были сорта из Красноярского края и Европейской части России.

Полученный уровень урожайности картофеля, даже в условиях невысокой цены реализации (12 руб/кг продовольственного картофеля), позволяет считать культуру высокодоходной. Уровень рентабельности производства варьировал, в зависимости от группы происхождения сортов, от 125 до $193 \%$.

\section{Выводы}

1. Установлено, что лучшей селекционной проработкой по всем показателям (урожайность, качество, экономическая эффективность) обладают сорта сибирской селекции.

2. Лучшей экономической эффективностью обладают сорта по происхождению из Красноярского края и Европейской части России.

\section{Рекомендации селекционным учреждениям}

1. Рекомендовать сорта картофеля для включения их в селекцию на продуктивность: Красноярский ранний, Памяти Рафика, Аризона, Танай, Невский.

2. При селекции на повышенное содержание крахмала - Памяти Рафика, Накра, Хозяюшка, Адретта и Метеор.

\section{Список литературы / References}

1. Симаков Е.А. Как вырастить ранний картофель // Вестник овощевода. 2009. № 1. С. 44-47.

Simakov E.A. How to grow early potatoes // Vestnik ovoshchevoda. 2009. № 1. P. 44-47 (in Russian).

2. Рычков В.А. Бурлов С.П. Селекция ранних и среднеранних сортов картофеля // Проблемы устойчивого развития регионального АПК: материалы научно-практической конференции. 2006. С. 79-82.

Rychkov V.A. Burlov S.P. Selection of early and sredneranny grades of potatoes // Problems of sustainable development of regional agrarian and industrial complex: materials of a scientific and practical conference. 2006. Р. 79-82 (in Russian).

3. Чураков А.А., Халипский А.Н., Ступницкий Д.Н., Абдураимов П.О. Направления селекции и особенности оригинального семеноводства картофеля в Красноярском ГАУ // В сборнике: Адаптивность сельскохозяйственных культур в экстремальных условиях Центрально- и Восточно-Азиатского макрорегиона материалы симпозиума с международным участием, 2018. С. 73-84.

Churakov A.A., Khalipskiy A.N., Stupnitskiy D.N., Abduraimov P.O. Directions of selection and features of the original potato seed in the Krasnoyarsk State Agrarian University // In the collection: Adaptability of crops in extreme conditions of the Central and East Asian macroregion symposium materials with the international participation, 2018. P. $73-84$ (in Russian).

4. Доспехов Б.А. Методика полевого опыта (с основами статистической обработки результатов исследований). М.: Агропромиздат, 2012. 352 c.

Dospekhov B.A. Methods of field experience (with the basics of statistical processing of research results). M.: Agropromisdat, 2012. 352 p. (in Russian).

5. Халипский А.Н. Изучение экологического эффекта разных сортов картофеля // Докл. и сообщ. генетико - се- 
лекционной школы (19-23.04.1999). РАСХН. Сиб. отделение СибНИИРС. Новосибирск, 2000. С. 338-340.

Khalipskiy A.N. Study of the environmental effect of different varieties of potatoes // Dokl. i soobshch. genetiko - selektsionnoy shkoly (19-23.04.1999). RASKhN. Sib. otdeleniye SibNIIRS. Novosibirsk, 2000. P. 338-340 (in Russian).

6. Симаков Е.А. Современные тенденции развития селекции на улучшение питательной ценности кар тофеля // Успехи современной науки. 2017. Т. 2. № 10. C. $44-50$.

Simakov E.A. Current trends in the development of breeding for improving the nutritional value of potatoes // Uspekhi sovremennoy nauki. 2017. V. 2. № 10. P. 44-50 (in Russian).
7. Коршунов А.В., Филиппова Г.И., Гаитова Н.А., Митюшкин А.В., Кутовенко Л.Н. Управление содержанием крахмала в картофеле // Аграрный вестник Урала. 2011. № 2. C. $47-50$.

Korshunov A.V., Filippova G.I., Gaitova N.A., Mityushkin A.V., Kutovenko L.N. Control of Starch Content in Potato // Agrarny vestnik Urala. 2011. № 2. P. 47-50 (in Russian).

8. Калинина Л.А., Новиков А.В. Спрос на картофель в Иркутской области // Вестник Брянской государственной сельскохозяйственной академии. 2012. № 2. С. 3-7.

Kalinina L.A., Novikov A.V. Demand for potatoes in the Irkutsk region // Vestnik Bryanskoy gosudarstvennoy selskokhozyaystvennoy akademii. 2012. № 2. P. 3-7 (in Russian). 